\title{
Probability learning in the T-maze as a function of proportion of reinforcement
}

ROGER P. MELERA

BROOKLYN COLLEGE OF THE CITY UNIVERSITY OF NEW YORK

Two groups of rats received different proportions of reinforcement in a T-maze probability learning experiment. Overshooting of the matching asymptote was obtained. When the real rats were compared with their theoretical counterparts, stat rats, there was close agreement of gross response structure, but not in the detailed response structure.

Two-choice probability learning experiments make some proportion of reinforcement available to $S$ for each alternative response. A theory proposed by Estes \& Straughan (1954) predicts that at asymptote Ss' responses match the proportion of reinforcement being used. They have obtained matching results using human Ss. Estes \& Lauer (1957) have reported matching results with rats in a $\mathrm{T}$-maze. Behrend \& Bitterman (1961) have concluded, however, that the matching prediction has not been supported by the experimental results. In their own studies they obtained some maximizing rather than matching results. Possibly, however, their experimental procedure did not satisfy the condition of symmetry. That is, Estes and Straughan's theory assumes that the same amount of learning occurs if, for example, $\mathrm{S}$ responds to the right and is reinforced, or responds to the left but is reinforced on the right. The procedure used in the present experiment was designed to satisfy the assumption of symmetry, and was similar to one used by Revusky (1961). On any trial when $\mathrm{S}$ responds to the nonreinforced side he is returned to the start box, retracing being prevented. This procedure is repeated until $S$ responds to the reinforced goal box. Theoretical justification for using a nonreinforced procedure is based on results obtained by Weinstock et al (1965) who, using rats in a T-maze, found that noncorrection trials left the probability of choice unchanged.

However, some of the stimulus components present when $\mathrm{S}$ first responds will most likely be absent when subsequent responses are made on the same trial. In Yiew of the Weinstock et al results, the conditioned status of the components which drop out will presumably remain unchanged. As a result of stimulus components dropping out a larger rate of learning will occur from trials on which $\mathrm{S}$ responds immediately to the reinforced side. This leads to a two-operator model presented by Bush \& Mosteller (1955) which generally predicts overshooting of the matching result, the rates of learning and the proportions of reinforcement determining the amount of overshooting. It was to be decided on the basis of asymptotic data which of the two plausible learning models is applicable, learning rate parameters estimated and detailed comparisons made between real and "stat" rats.

Method

The Ss were 84 naive female albino rats $90-110$ days old. A T-maze 5 in. high and, except for the goal boxes, 5 in. wide throughout was used. It had a 9-in.-long start box, a 24-in.-long stem and two 18-in.-long arms. The goal boxes were $7 \mathrm{in}$. wide and $6 \mathrm{in}$. long to provide a recessed drinking alcove in the side of the goal box closest to the start box. On nonreinforced trials an aluminum slide could be inserted into either goal box alcove preventing access to the drinking tube.

An $18 \mathrm{hr}$. water deprivation schedule was initiated after which Ss were randomly assigned to the four experimental groups, 80-20 right, 80-20 left, 60-40 right and 60-40 left. The numbers $80-20$ and $60-40$ designate the proportion of reinforcement, so that, for example, the 80-20 $\mathrm{R}$ group received water reinforcement on the right $80 \%$ and on the left $20 \%$ of the trials. Reinforcements were assigned randomly by blocks of 10 trials. All Ss were given 80 acquisition trials at two per day using a 3-hr. intertrial interval. When $\mathrm{S}$ entered either arm the door behind it was shut preventing retracing. If $\mathrm{S}$ ran to the reinforced side the run was terminated $10 \mathrm{sec}$. after the initiation of drinking. If $\mathrm{S}$ ran to the nonreinforced side it was removed and returned to the start box. This procedure was repeated until $\mathrm{S}$ ran to the reinforced goal box.

Results

Figure 1 shows the acquisition curves for the 80-20 and the $60-40$ groups in blocks of 10 trials. The $A_{1}$ responses represent the percentage of first choice responses to the larger proportion side. To determine whether the overshooting of the matching asymptote was statistically significant $t$ tests were performed for both the 60-40 and the 80-20 groups, yielding $t$ values of 3.83 (41 df) and 3.75 (41 df), respectively, both being significant at the $5 \%$ level. Since overshooting was obtained it was decided to use the two-operator model. Based on early learning performance of the real Ss, the $\theta$ values obtained for trials on which Ss were reinforced immediately, or $\theta_{1}$, was .13 and the value obtained for correction trials, or $\theta_{2}$, was .08 . Then 84 stat rats were generated and given 80 "learning trials" under learning conditions similar to those given to the real Ss.

As may be seen from Fig. 1 there is close agreement at asymptote between real and stat rats. For the last 40 trials the $80-20$ real rats totaled 1427 larger proportion side responses while their statistical counter- 


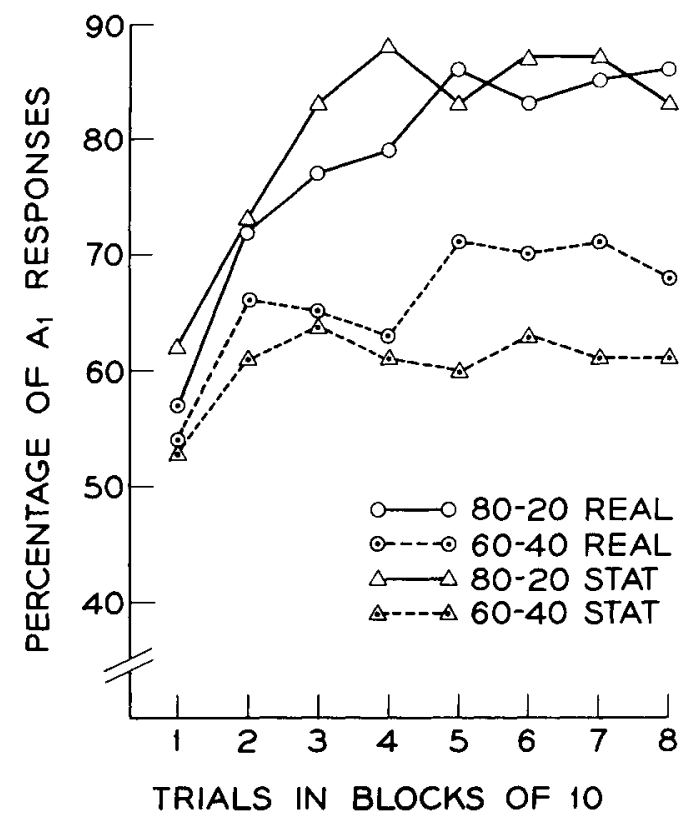

Fig. 1. Acquisition curves for the 80-20 and the 60-40 groups.

parts made 1429 such responses. The $60-40$ real rats made 1173 larger proportion side responses while the 60-40 stat rats made 1028 such responses. Tests for a mean difference between the real and stat rats, using the last 40 trials, yielded a $t=.17$ (82 df) for the $80-20$ $R-L$ real versus $80-20 \mathrm{R}-\mathrm{L}$ stat rats, and $t=.91$ (82 df) for the real versus stat 60-40 groups. Both of these $t$ values are nonsignificant.

An analysis of variance yielded a significant difference $(F=24.59 ; \mathrm{df}=1 / 80)$ between the $80-20$ and 60-40 groups.

To determine whether the real and stat rats showed detailed agreement in their responding, 41 statistics were computed showing the "fine structure"' of their behavior. For the $80-20$ groups, 8 out of the 41 comparisons between the stat versus the real rats were significantly different at the $5 \%$ level. For the 60-40 groups there were 15 out of 41 such differences. Discussion

Although there was agreement at asymptote between the real and stat rats, a large number of significant differences were obtained on the "fine structure" of the data. There are two possible reasons for this discrepancy. First, variance on the proportion of responses at asymptote was larger for the 60-40 real group than for the 60-40 stat group. Some real Ss gave a higher number of responses while other Ss gave a lower number of responses than the stat rats. The high and low response rates balanced each other out in the computed means. These differences were detected by some of the $41 \mathrm{t}$ tests which compare specific rather than gross performance differences.

Second, theoretical agreement at asymptote was made on the basis of the last 40 trials, whereas all 80 trials were used for the 41 comparisons. While overshooting of the matching asymptote occurred for both 80-20 and 60-40 Ss, overshooting occurred during the early trials as well as the later ones only for the 60-40 group, contributing to the large number of significant differences found for this group.

As a result of the close agreement at asymptote between the stat and the real rats, and the large number of significant differences obtained for the detailed comparisons made between these groups, it may be concluded that the model provides only a first order approximation and fails to deal with the fine structure of the data.

\section{References}

Behrend, E. R., \& Bitterman, M. B. Probability matching in the fish. Amer. J. Psychol., 1961, 74, 542-551.

Bush, R. R., \& Mosteller, F. Stochastic models for learning. New York: Wiley, 1955.

Estes, W. K., \& Lauer, D. W. Conditions of invariance and modifiability in simple reversal learning. J. comp. physiol. Psychol., 1957, 50, 199-206.

Estes, W. K., \& Straughan, J. H. Analysis of a verbal conditioning situation in terms of statistical learning theory. $J$. exp. Psychol., $1954,47,225-234$

Revusky, S. H. Nonreinforced trial procedure for probability learning. Science, 1961, 134, 328-329.

Weinstock, S., North, A. J., Brody, A. L., \& LoGuidice, J. Probability learning in the T-maze with noncorrertion. J. comp. physiol. Psychol, , 1965, 60, 76-81.

\section{Note}

1. This report is based upon a master's thesis submitted to Brooklyn College, C.U.N.Y., and carried out under the direction of Dr. Solomon Weinstock whose advice and assistance is gratefully acknowledged. 